\title{
أثر تذبذب أسعار اللحوم الحمراء علي العمالة والتشغيل (دراسة حالة محافظة البحيرة)
}

\author{
كمال سلامة، إلهام شعبان عبد السلام برجل، دعاء إبراهيم عبد الحميد هاشم \\ معهد بحوث الاقتصاد الزر اعي- مركز البحوث الزراعية
}

\section{| (ماخص}

استهدف البحث التعرف على أثز تذبذب أسعار اللحوم الحمراء علي العمالة والتتغيل بمحافظة البحيرة لوضع الحلول والمقترحات التي من شانها المحافظه علي إستقرار وثبات أسعار اللحوم الحمر اء في الأسواق المصرية، وذلك من خلال در اسة الأهداف الفرعية التالية: 1-

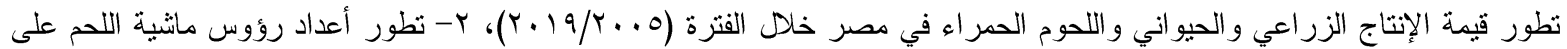

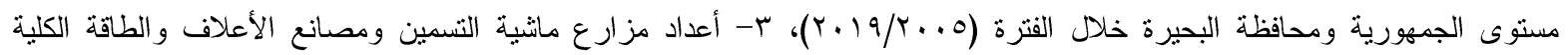

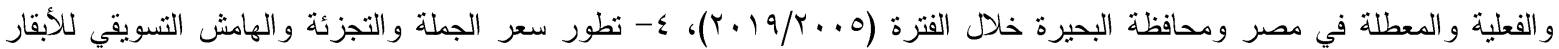

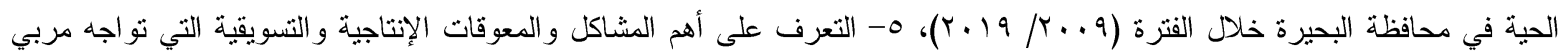

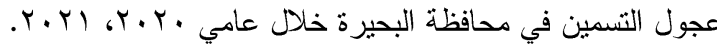
وتوصلت الدر اسة إلي عدة نتائج أهمها: (1) بلغ منتوسط نسبة قيمة إنتاج اللحوم الحمراء في مصر من قيمة الإنتاج الزراعي و الإنتاج

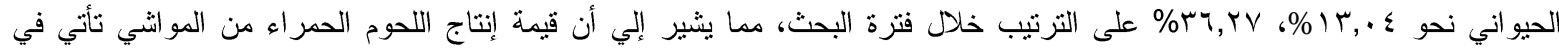

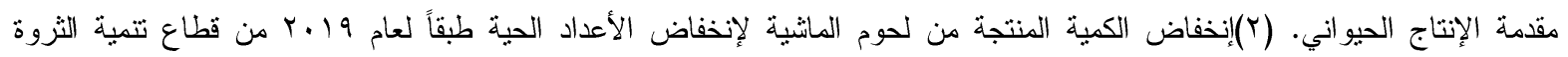

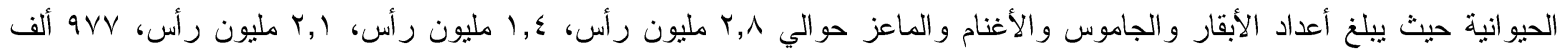

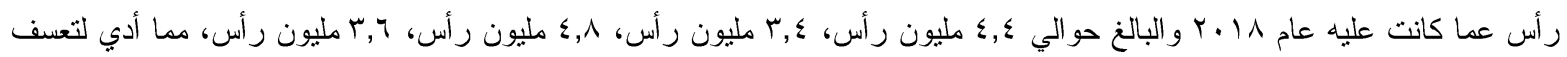
كثير من المربين عن التربية في ذلك الوقت مما أثز سلباً أيضاً علي العمالة في قطاع الإنتاج الحيواني. (r) بلغت نسبة منوسط الطاقة المعطلة للطاقة الكلية في محافظة البحيرة بالنسبة للجمهورية بلغت نحو ^،؛ 9\% مما يتطلب الإهتمام بالمز ارع المعطلة بمحافظة البحيرة

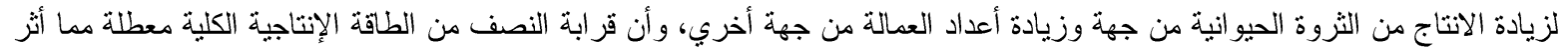

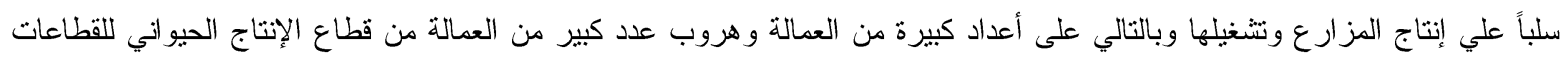
الأخري. (ع) أكثر من ثلثي الطاقة الإنتاجية الكلية لمصانع أعلاف الماثية في مصر معطلة مما أثر سلباً علي إنتاج مصانع أعلاف الماثية في مصر ونتغيلها وبالتالي علي أعداد كبيرة من العمالة بها. (0) المنتج يحصل علي نحو

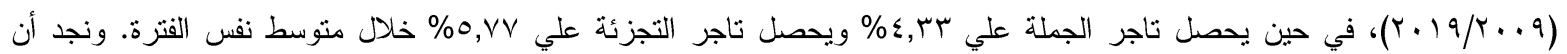

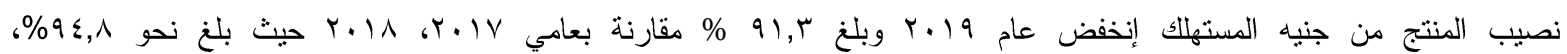

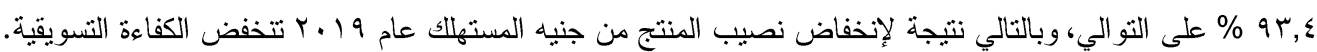

الكلمات المفتاحية: اللحوم الحمر اء- التشغيل- جنيه المستهلك- المشاكل الإتتاجية و التسويقية- محافظة البحيرة. هاماً في الاقتصاد الزراعي وتعتبر أنشطة الإنتاج

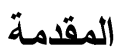
الحيو اني من أهم الأنشطة الرئيسية لقطاع الزراعة إذ أنها تسهم في رفع مستوى الأمن الغذائي وتحسين نوعية الغذاء لكونها من أهم مصادر البرونين الحيواني الضروري للإنسان، كما يُعد إنتاج اللحوم من أهم الأنشطة داخل قطاع الإنتاج الحيواني، حيث يبلغ الدخل الذي حققه هذا القطاع عام 19 . r حوالي جنيه يمثل نحو 0, • 1\% من إجمالي الدخل الزراعي ونحو 9,9\%\% من قيمة دخل الناتج من قطاع الإنتاج

تهنم الدولة بالإنتاج الزراعي بشقيه النباتي و الحيو اني لتحقيق قدر من الإكتقاء الذاتي من المنتجات الزراعية النباتية والحيوانية، ولتوفير متطلبات القطاعات الاقتصادية الآخرى من الخامات و المواد

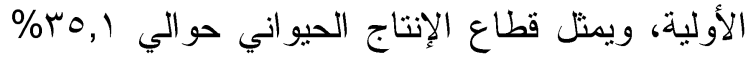
من إجمالي قيمة الإنتاج الزر اعي البالغ حوالي r, گسه مليار جنيه، مما يجعل هذا القطاع يؤدي دوراً اقتصادياً 


\section{'الأهداف البحثية}

استهدف البحث بصفة رئيسية التعرف على تذبذب أسعار اللحوم الحمر اء على العمالة والتشغيل بمحافظة البحيرة وذلك من خلال دراسة الأهداف الفرعية التالية: 1- تطور قيمة الإنتاج الزراعي والحيو اني و اللحوم

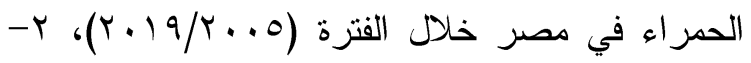
تطور أعداد رؤوس مانثية اللحم علي مستوي

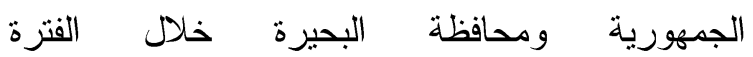

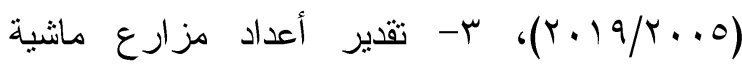
التسمين ومصانع الأعلاف و الطاقة الكلية و الفعلية و المعطلة في مصر ومحافظة البحيرة خلال الفترة

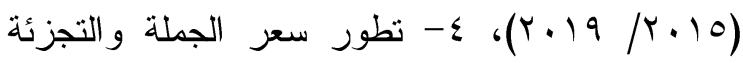
و الهامش التسويقي للأبقار الحية في محافظة البحيرة

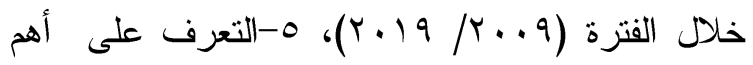
المشاكل و المعوقات الإنتاجية و التسويقية التي تواجه

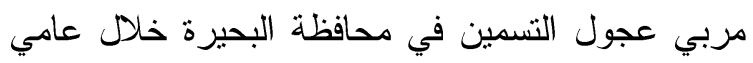

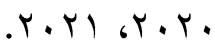

\section{الأسلوب البحثي ومصادر البيانات}

اعتمد البحث في تحقيق الأهداف المنشودة منه على كل من التحليل الاقتصادي الوصفي و التحليل الإحصائي، حيث استتد على مصدرين رئيسيين للبيانات

(1) البيانات الثانوية المنشورة وغير المنشورة فى العديد من الهيئات مثل: الجهاز المركزي للتعبئة العامة والإحصاء وقطاع الثئون الإقتصادية

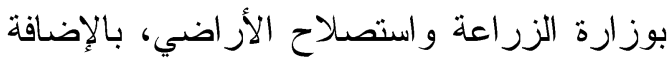
إلى البيانات التي أمكن الحصول عليها من شبكة التها

$$
\text { الإتصالات و المعلومات (Internet). }
$$

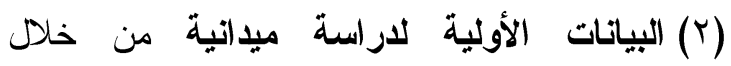

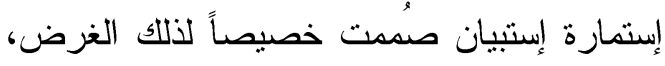
تم تجميعها عن طريق المقابلة الثخصية لمربي عجول التسمين داخل الأسواق الرئيسية لمحافظة

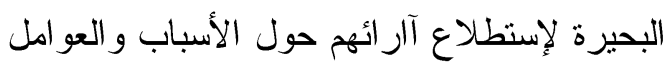

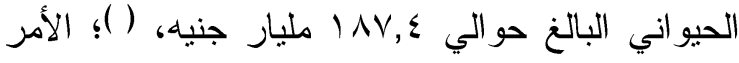
الذي يتطلب ضرورة تطوير وتتمية قطاع الإنتاج الحيو اني بصفة عامة وقطاع إنتاج اللحوم بصفة خاصة

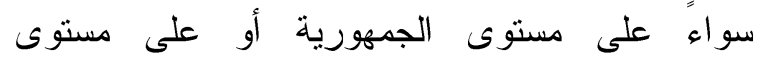

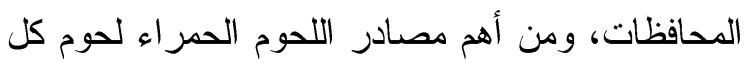

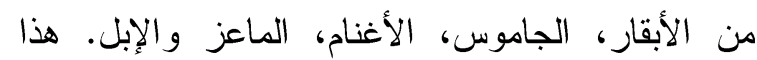

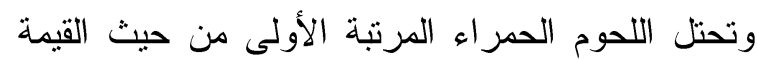

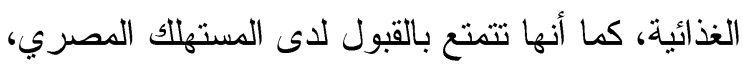

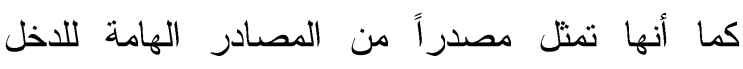

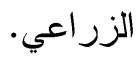

\section{المشكلة البحثية}

تتمثل المشكلة البحثية في تذبذب أسعار اللحوم

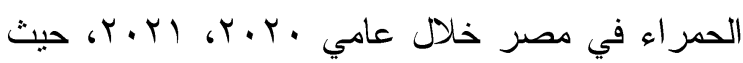
انخفضت أسعار المنتج و الجملة و التجزئة للحوم الحمر اء هُ هاء من حوالي 07، 09، ـ آجنيه/كجم علي الترتيب خلال

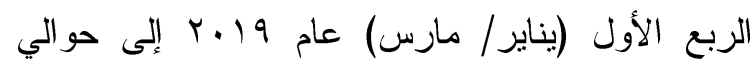

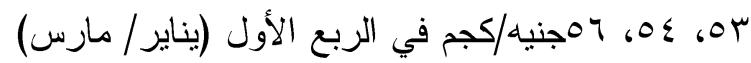

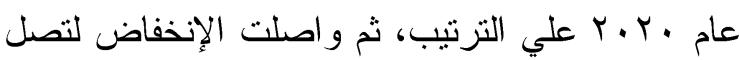

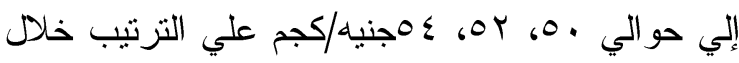

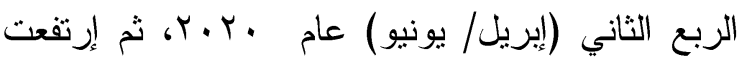

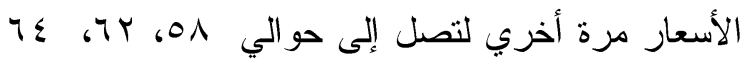

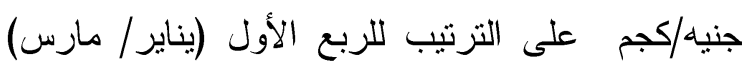

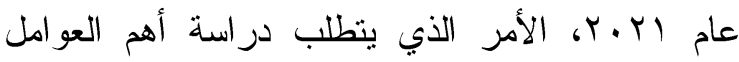
والأسباب التي أدت إلي تذبذب أسعار اللحوم في الأسواق المصرية بصفة عامة ومحافظة البحيرة بصفة

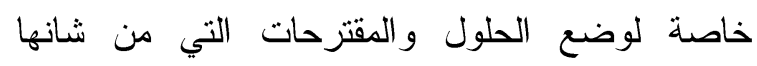

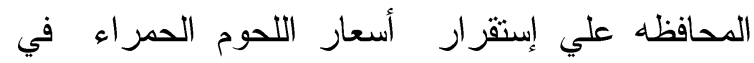

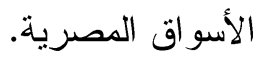
( ) وزارة الزراعة واستصلاح الأراضي، قطاع الشئون الاقتصادية، نشرة الدخل

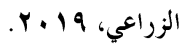


من سوق كفر الدوار و.r إستمارة من سوق أبو المطامير، • (إستمار ات من سوق أبوحص.

\section{النتائج البحثية}

أولاً: تطور قيمة الإنتاج الزراعي والحيواني واللحوم

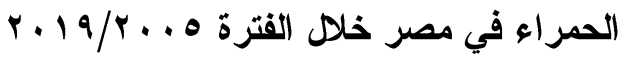

يتبين من البيانات الوارده بالجدول (1) و الثكل رقم

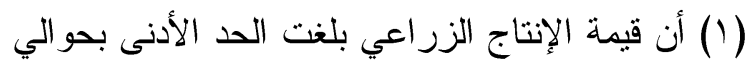

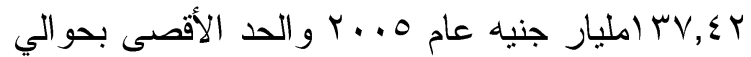

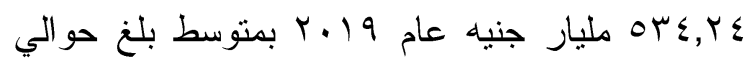

مليار جنيه وبمقدار زيادة سنوية معنوية TAV,YT

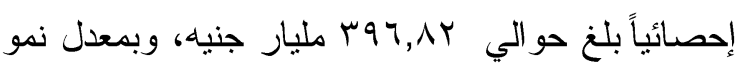

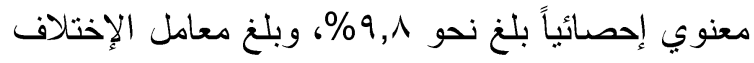

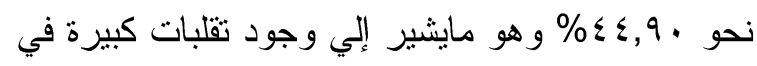

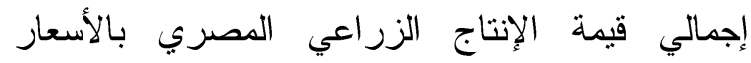

الجارية خلال فترة البحث.
التي أدت إلي تذبذب أسعار اللحوم خلال

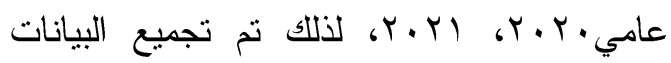

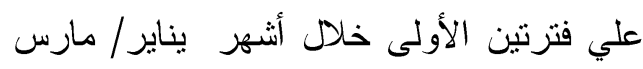

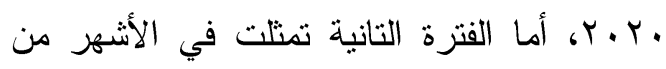
يناير/ مارس /Y.r.Y. وتمثلت الأسواق الرئيسية لمحافظة البحيرة التي تم تجميع البيانات منها

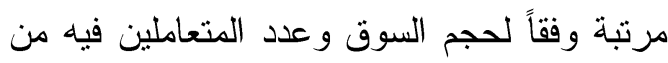

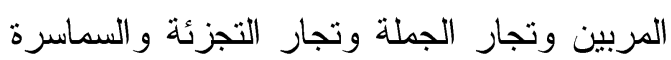
في الأسواق التالية:سوق دمنهور العمودي ويقام يوم الأحد وهو يعتبر أكبر أسواق المحافظة، سوق

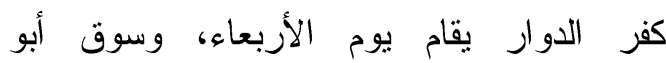
المطامبر يقام يوم الجمعة، وسوق أبوحمص يقام يوم الثلاثاء.

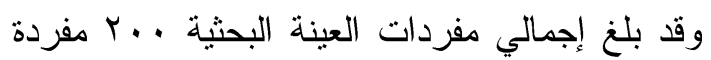

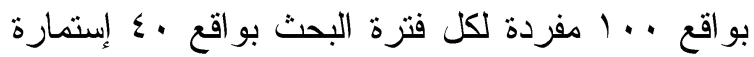

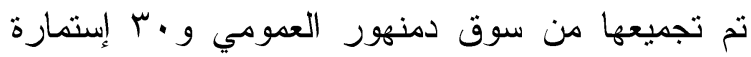

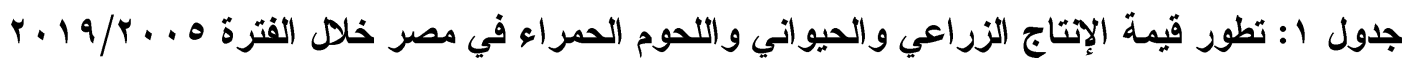

\begin{tabular}{|c|c|c|c|c|c|c|}
\hline قالحمة الحيمة الأحتاج من & قالقيمة اللَمة الإعتاج من & قالقيمة الإنتاجة الإتياج & قالحمة اللحوم & (ألحيو ألنيتاج & (مليونة الإعتياج & السنوات \\
\hline r, r. & $11, r \wedge$ & $r 7,17$ & $100 . r$ & $\sum 97 \wedge 9$ & $1 T V \varepsilon 19$ & r...o \\
\hline ro,AT & IT,AT & ro,VV & INAIV & $O Y \leqslant V O$ & IEYTAY & $r \ldots r$ \\
\hline 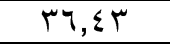 & $|Y, 9|$ & $\mu_{0, \varepsilon} \leqslant$ & $r .1 Y q$ & $00 Y 4$. & $1009 \leqslant 0$ & $r \ldots V$ \\
\hline rr,l. & 11,7 . & ro,. $\varepsilon$ & rorr & 70.7. & 110747 & $r \ldots \Lambda$ \\
\hline$r 0, \cdot 1$ & $I Y, Y \wedge$ & $\mu 4, \Sigma 9$ & $r \leqslant Y \cdot r$ & $791 \%$. & $1 \wedge 9 \leqslant \mu \wedge$ & $r \ldots q$ \\
\hline rq,.. & $|r, r|$ & M4,97 & rVAON & VVTAY & r.9Tos & $r+1$. \\
\hline$r \lambda, r \mu$ & $1 Y, 91$ & $r \mu, A V$ & $r Y \leqslant 00$ & 1 $\Sigma 779$ & $r \leqslant 9919$ & $r .11$ \\
\hline$r 4, \Sigma \Lambda$ & $\mid Y, 1 \leq$ & 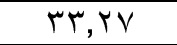 & $r \leqslant 0 \leqslant 0$ & $\Lambda \wedge 9 \vee$. & YTV $\{Y \varepsilon$ & T.IY \\
\hline$r 0, r \mu$ & IY,YT & $T \leqslant, T Y$ & TVYA. & $9 \vee \vee \wedge 1$ & TAY $\leqslant Y \varepsilon$ & $r .14$ \\
\hline Tr,TH & $|Y, Y|$ & $\mu 廿, \mathrm{V \mu}$ & $\{r T r \mid$ & 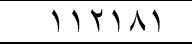 & $r .0 \leqslant 1 \leqslant$ & $Y \cdot 1 \varepsilon$ \\
\hline$\varepsilon ., 79$ & $10, Y 4$ & $r V, 01$ & $\{109 Y$ & $119 \varepsilon .7$ & TIATTY & $r .10$ \\
\hline$\leqslant 1,09$ & $10,4 Y$ & $r V, 00$ & OOVOY & $1 T \leqslant .00$ & ro7901 & $r .17$ \\
\hline$\varepsilon \cdot, 04$ & $1 \leq, V$. & M , YO & $7 \wedge 9 \vee 1$ & $1 V \ldots Y \varepsilon$ & $\sum 79 Y \cdot Y$ & $r . I V$ \\
\hline rᄉ, rV & $1 \leqslant, \varepsilon$. & TY,OY & $V Y \cdot\{1$ & IAVVV. & $0 \ldots \leqslant 1 \pi$ & $r \cdot 1 \Lambda$ \\
\hline$r 9, \wedge 9$ & $1 \cdot, \sum \Lambda$ & $\mathrm{ro}_{\mathrm{O}} \cdot \mathrm{V}$ & $07 \ldots$ & $1 \wedge V+41$ & Or $\leqslant Y \leqslant \varepsilon$ & $r .19$ \\
\hline \multirow[t]{3}{*}{$r V, r}$. & $1 r, r q$ & $r q, \ldots 1$ & 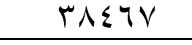 & $1 . r \leqslant 1 V$ & YAVYYI & المتوسط \\
\hline & & & $\{\vee, T)$ & $\leqslant 0,9 \leqslant$ & $\varepsilon \varepsilon, q$. & معامل الإختلاف\%\%(1) \\
\hline & & & ${ }^{* *}, \cdot, \wedge$ & $\left.{ }^{* *}\right)$. & ${ }^{* * *} 9, \wedge$ & معدل التغير (\%) \\
\hline
\end{tabular}




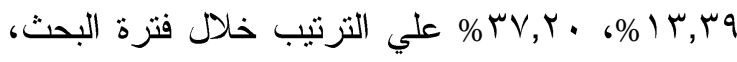
ولاشك أن هذه النسبة تدلل بوضوح علي أهمية قطاع

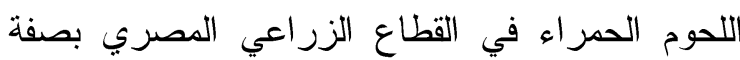
عامة وقطاع الإنتاج الحيو اني بصفة خاصة؛ مما يثير

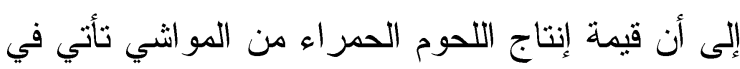

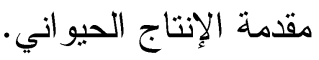

ثانياً: تطور أعداد رؤوس ماثية اللحم علي مستوى

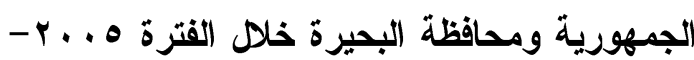

$r+19$

(1) تطور أعداد رؤوس ماثية اللحم في مصر : يتبين من بيانات الجدول (Y) أن:

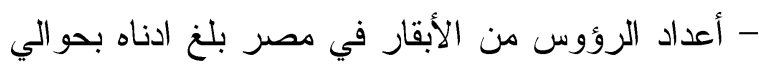

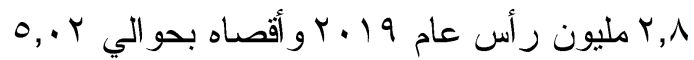

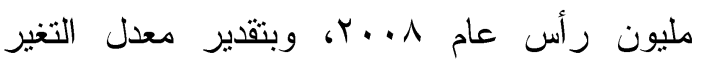
السنوي لأعداد الرؤوس من الأبقار تبين أنه يأخذ معدل تناقص سنوي قدر بنحو 0,1\% وهو معنوي

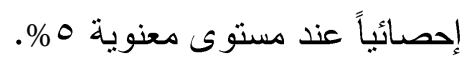
- أعداد الرؤوس من الجاموس في مصر بلغ ادناه

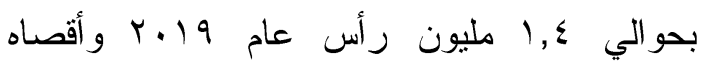

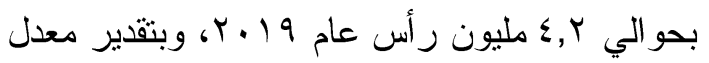
التغير السنوي لأعداد الرؤوس من الجاموس تبين

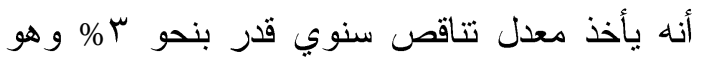
معنوي إحصائياً عند مستوى معنوية (1\%.
وبدراسة تطور إجمالي قيمة الإنتاج الحيواني في

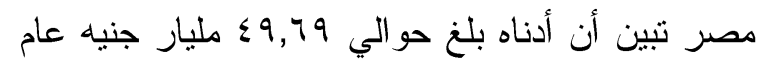

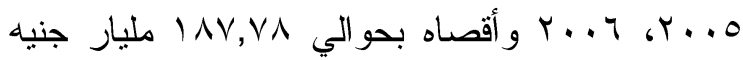

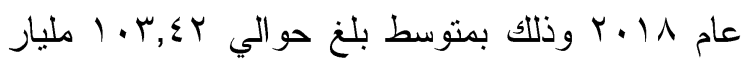

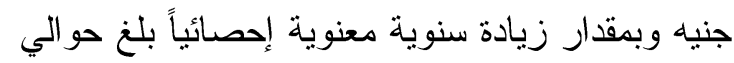

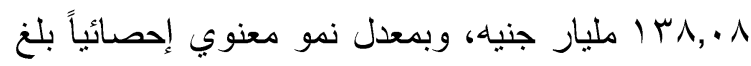

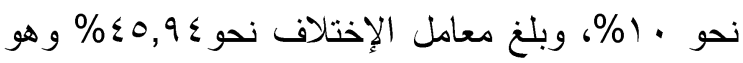
مايشير إلي وجود نقلبات كبيرة في إجمالي قيمة الإنتاج الحيو اني المصري بالأسعار الجارية خلال فترة البحث. وقد بلغ متوسط نسبة قيمة الإنتاج الحيو اني من قيمة لهابه

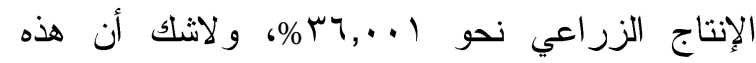
النسبة تدلل بوضوح على أهمية قطاع الإنتاج الحيواني في القطاع الزر اعي المصري. وبدراسة تطور إجمالي قيمة إنتاج اللحوم الحمراء في مصر تبين أنه بلغ أدناه بحو الي • 0,0 امليار جنيه

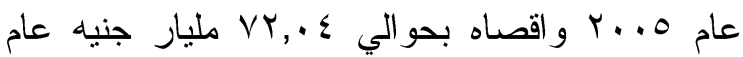

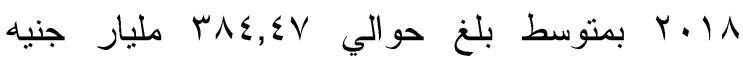

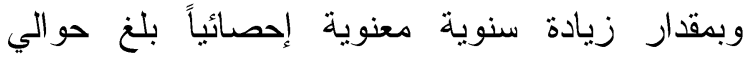

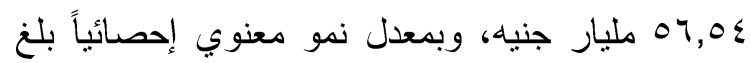

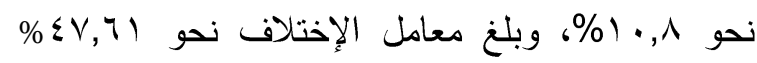
وهو مايشير إلي وجود تقلبات كبيرة في إجمالي قيمة

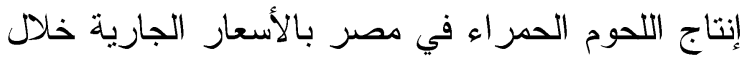

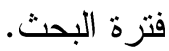
وقد بلغ متوسط قيمة إنتاج اللحوم الحمر اء في مصر من قيمة الإنتاج الزراعي والإنتاج الحيواني نحوم العاج

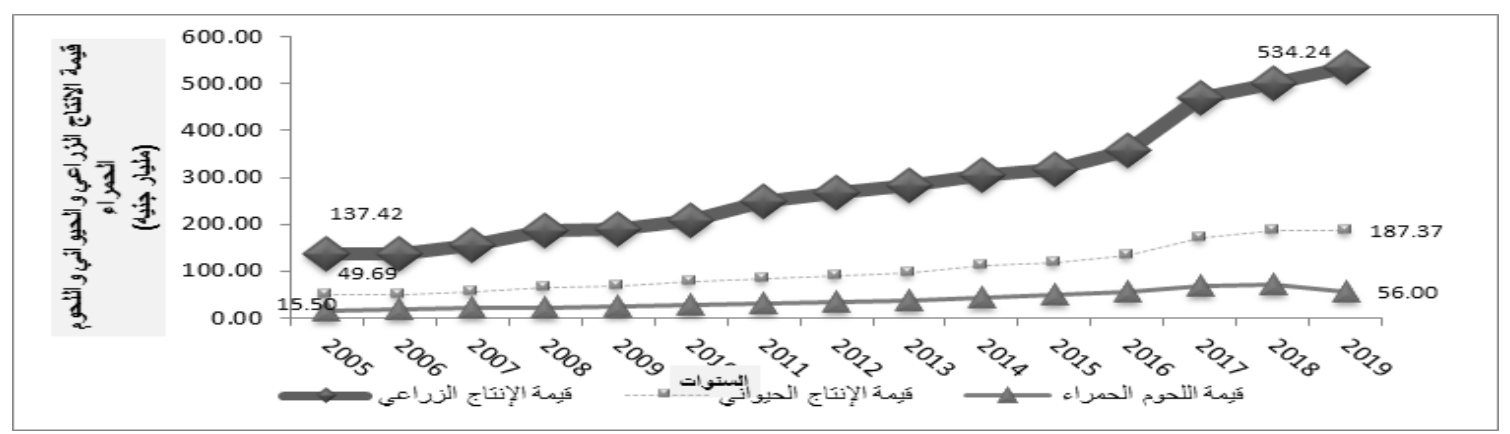

شكل ا: يوضح تطور قيمة الإتتاج الزراعي والحيو اني واللحوم الحمراء في مصر خلال الفترة (ه . . - -9 1 + ). 


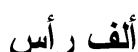

أعداد رؤوس الإبل

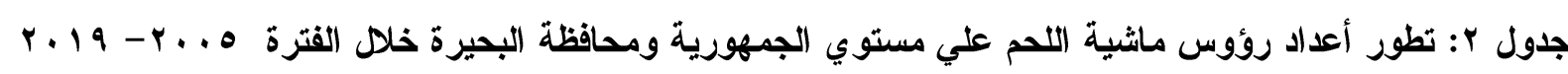

\begin{tabular}{|c|c|c|c|c|c|c|c|c|c|c|c|c|c|c|c|}
\hline \multicolumn{3}{|c|}{ اعداد رؤوس الإبل } & \multicolumn{3}{|c|}{ اعداد رؤوس الماعز } & \multicolumn{3}{|c|}{ اعداد رؤوس الاغنام } & \multicolumn{3}{|c|}{ اعداد رؤوس الجاموس } & \multicolumn{3}{|c|}{ اعداد رؤوس الابقار } & \multirow[b]{2}{*}{ السنوات } \\
\hline الألهمبية & البحيرة & الجمهورية & النسبية\% الأهمية & البحيرة & الجمهورية & النسبية\% & البحيرة & الجمهورية & $\begin{array}{c}\text { الأهمبية } \\
\text { \% }\end{array}$ & البحيرة & الجمهورية & $\begin{array}{c}\text { الأهمبية } \\
\text { \% }\end{array}$ & البحيرة & الجمهورية & \\
\hline א & 1 & $1 \leqslant r$ & $V \circ V$ & rMA & rג. & 1.81 & ovi & OTMY & 1180 & « & rN10 & $1 \leq a \wedge$ & TVY & $\leqslant \leqslant 10$ & r...o \\
\hline$\varepsilon \ldots$ & 7 & $1 \leqslant 1$ & Vor & rar & rAVY & 1. ar & $O \Lambda \Lambda$ & orro & 1181 & 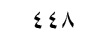 & rqu & $1 \leqslant$ aV & 79. & $\{71$. & $r \ldots r$ \\
\hline $18 r$ & v & $1 \cdot \varepsilon$ & $A$ A & rvi & \&YाI & ד8 & vro & $0 \leq 71$ & $1 \leqslant 8$. & ovi & $\varepsilon \cdot \leqslant r$ & $1 \leqslant 8 V$ & $v .9$ & \&qur & $r \ldots r$ \\
\hline 0.07 & v & $1 K 4$ & 981 & rar & ETrV & 1487 & vrq & $0 \leqslant 91$ & 11 ลV & $\leqslant 10$ & \&.or & $1 \leq \leqslant 1$ & $V T \varepsilon$ & $0 . \mathrm{rr}$ & $r \ldots \lambda$ \\
\hline$\leqslant$ & 7 & IrV & tor & $r V$. & \&1rq & $a d r$ & 01. & 0094 & $1 \cdot 8 r$ & 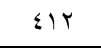 & rerq & Tr8 & .001 & soro & $r \ldots q$ \\
\hline$\leq 0$. & 。 & 111 & $7 \leqslant \leqslant$ & rฯq & $\leqslant 1 V_{0}$ & 98 & 019 & oor. & $1.8 \leq$ & r91 & rNis & IT84 & $0 \wedge$. & $\varepsilon V r q$ & $r .1$. \\
\hline$r 89$ & $r$ & ITr & $T \leqslant 1$ & rVY & EYOA & Arv & $\leq \leqslant 9$ & 0474 & 1.8. & $\leqslant r 4$ & rqג & $9 \leqslant 1$ & so. & $\leqslant \vee \lambda$. & $r .11$ \\
\hline ral & r & $1 \leqslant r$ & $7 \leqslant 1$ & rVq & $\leqslant r . q$ & Voo & «1. & $0 \leqslant r$. & 1.8. & \& ro & $\$ 170$ & $\Lambda a v$ & $\leqslant r q$ & $\leq 9 \leq 7$ & $r .1 r$ \\
\hline ral & $\varepsilon$ & lor & $1 \leqslant 0$ & rqu & \&lor & $v$ ar & « & $007 \varepsilon$ & 1.0. & $\leqslant 11$ & 4910 & $|r a|$ & 74. & $\leqslant V \leqslant 0$ & $r .1 T$ \\
\hline$r a t r$ & . & 101 & 10. & TVY & $\{1 \wedge \uparrow$ & Vor & «1 & $00 . r$ & 1. 1. & $\varepsilon 19$ & $r q \Sigma 9$ & 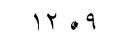 & ovi & \&VฯT & $r .1 \varepsilon$ \\
\hline rat & 1 & lor & $v a v$ & rq. & $\{0 \leqslant 7$ & 1.9 & $\leqslant \leqslant r$ & Tा & $1.8 \mathrm{~V}$ & $r \wedge \varepsilon$ & $r V \cdot r$ & $11 \ldots$ & orv & 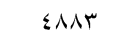 & $r .10$ \\
\hline Tor & 7 & 100 & $\Lambda d r$ & TYY & $\leq .1$. & $v \leqslant 9$ & $\varepsilon \cdot r$ & ord $\varepsilon$ & 1.87 & r^ई & roth & 1121 & 011 & ס סדו & $r .17$ \\
\hline rri & . & 107 & $9: 1$ & rT & rqvะ & 7.17 & אוד & or.o & 1189 & $\Gamma \wedge \varepsilon$ & r & $118 \mathrm{~V}$ & $\leqslant 99$ & $\varepsilon r A V$ & $r .1 v$ \\
\hline$v .4$ & 7 & 10 & $A d r$ & ra. & roVr & 910 & $\leqslant \leqslant r$ & 纟八r. & 1120 & 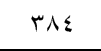 & $r \leq \leqslant 0$ & 1484 & orv & $\varepsilon r v q$ & $r .11$ \\
\hline$r g$. & $r$ & 91 & opr & $0 \leqslant$ & $9 \mathrm{VV}$ & 1.84 & Yrs & $r \cdot \lambda r$ & $14 \leqslant V$ & rro & $1 \leqslant r V$ & 11.19 & צr & $r \Lambda . q$ & $r .19$ \\
\hline $09 \leqslant V$ & vip. & $199 V \%$ & $11 \cdot, 1$ & $\leq r \cdot 1$, & ovars & $1 \leq$. or & VTYA & VVITY & $|v|, 9 \mid$ & $\pi \cdot V$ & 0017.0 & $110,1 \mathrm{r}$ & $\Lambda \leqslant V r$ & TATr & الإجمالي \\
\hline \multirow[t]{2}{*}{$r, r}$. & $0,1$. & Vו, זسו & $V, Y$ & r, ז'ו & ז & $9,1 V$ & $\{\Lambda \mid A V$ & $01 V_{0} \leqslant \mathrm{~V}$ & 4ד, 11 & $\leqslant 1 \% \wedge$. & MYVV $\leqslant$ & KY, & $07 \leqslant A V$ & EOVo, & المتوسط \\
\hline & $\vec{\varepsilon}(\xi)$ & (4) & & (iz) & (z) & & $* *(6)$ & *) & & $* *$ ( ) & $* *$ ( ) & & $* *(r)$ & ${ }^{*}\left(\begin{array}{ll}0 \\
0\end{array}\right)$ & معل التغير \% \\
\hline
\end{tabular}

*معنوية عند مستوي معنوية 0\%، *** معنوية عند مستوي معنوية (\%)، () و القيم بين الأفو اس تدل أنها سالبة.

المصدر : وزارة الزر اعة وإستصلاح الأر اضى، قطاع الثئون الإقتصادية، نشرة إحصاءات الثروة الحيو انية، أعداد مختلفة. 


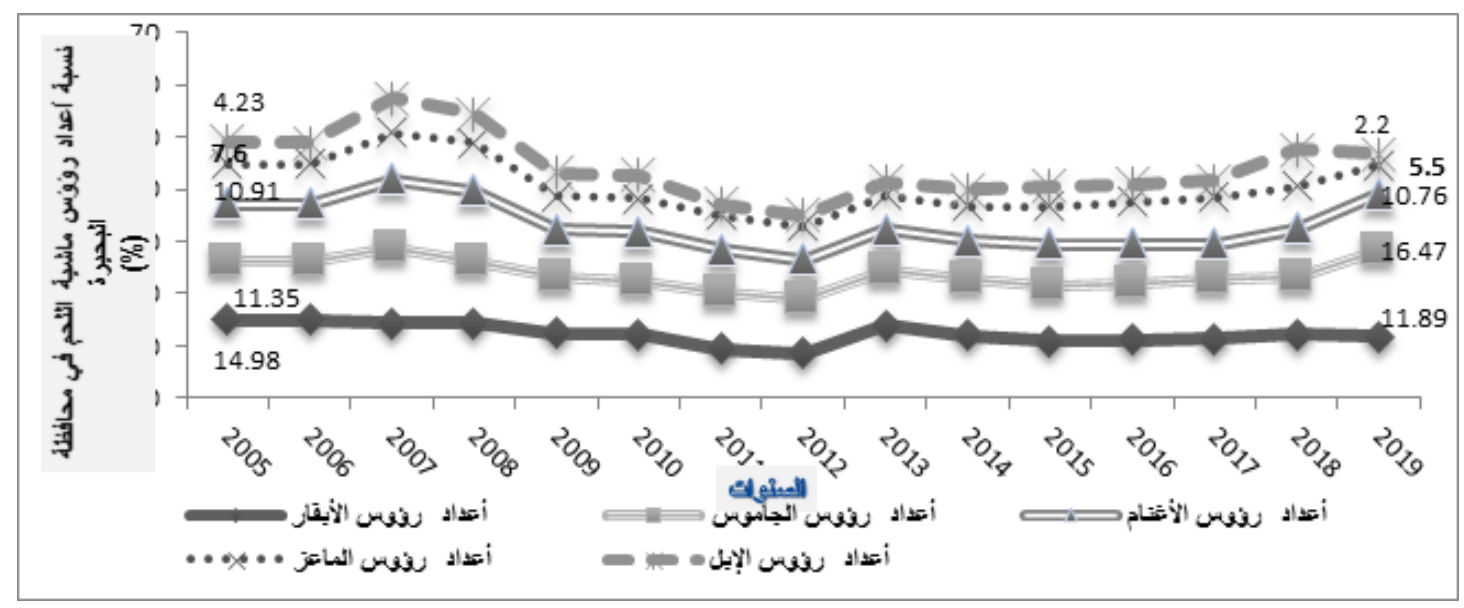

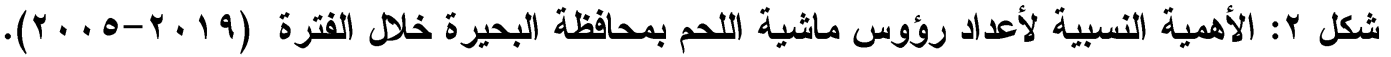

التغير السنوي لأعداد الرؤوس من الأبقار تبين أنه

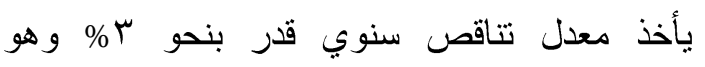

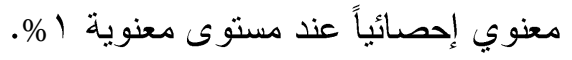

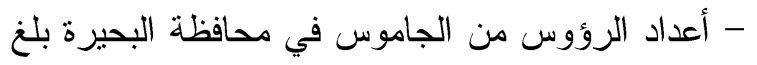

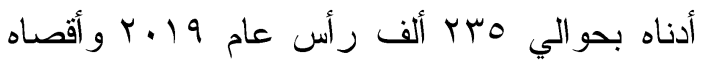

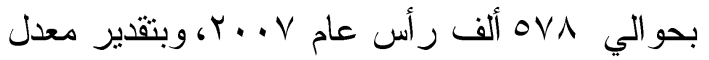
التغير السنوي لأعداد الرؤوس من الجاموس تبين

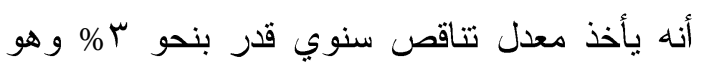

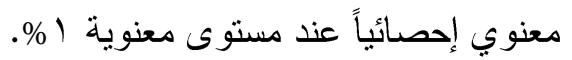

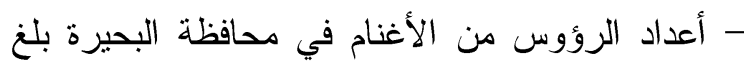

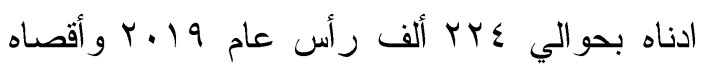

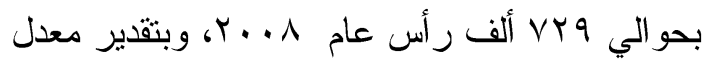
التغير السنوي لأعداد الرؤوس من الأغنام تبين يأخذ معدل نتاقص سنوي قدر بنحو ٪\% وهو معنوي

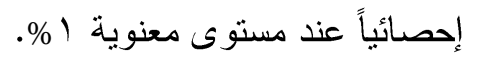

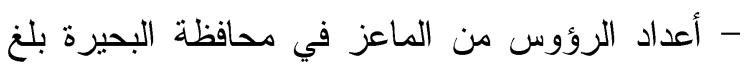

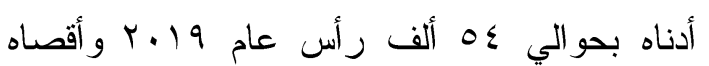

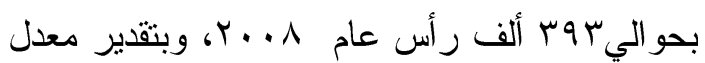
التغير السنوي لأعداد الرؤوس من الماعز تبين أند لم تتبت المعنوية احصائياً.
- أعداد الرؤوس من الأغنام في مصر بلغ ادناه بحو الي

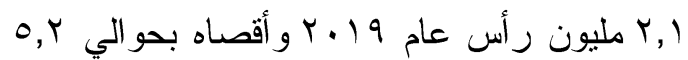

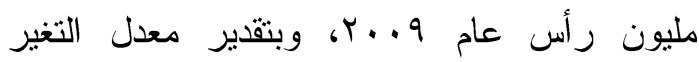
السنوي لأعداد الرؤوس من الأغنام تبين أنه يأخذ

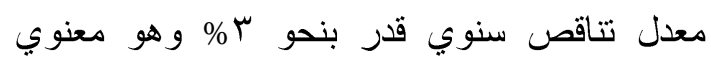

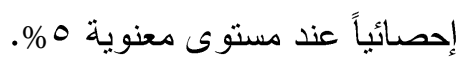
- أعداد الرؤوس من الماعز في مصر بلغ أدناه بحو الي بلي 9VV

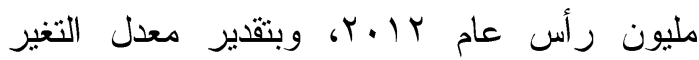
السنوي لأعداد الرؤوس من الماعز تبين أنه لم تتبت المعنوية احصائياً. - أعداد الرؤوس من الإبل في مصر بلغ ادناه بحوالي

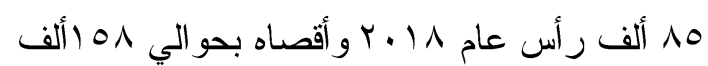
رأس عام § ا.ب، وبتقدير معدل التغير السنوي لأعداد الرؤوس من الأبل تبين أنه لم تتبت المعنوية احصائياً. (r) تطور أعداد رؤوس ماثية اللحم في محافظة

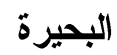
يتبين من بيانات الجدول (Y) أن: - أعداد الرؤوس من الأبقار في محافظة البحيرة بلغ بلغ البان

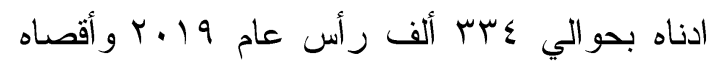

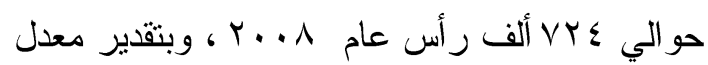




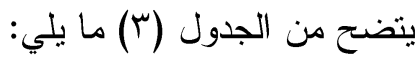

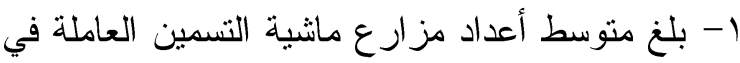

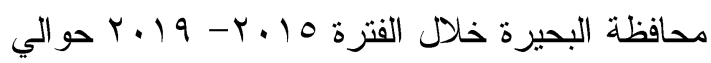

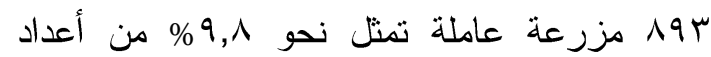

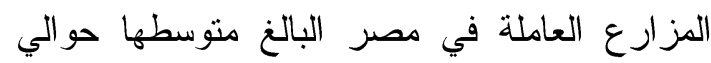
ا IV أو مزرعة، بينما بلغ متوسط طاقتها الإنتاجية

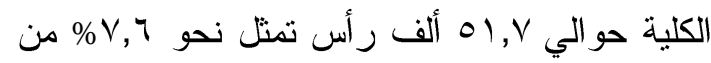

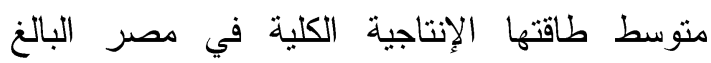
حوالي اNT ألف رأس ومتوسط طاقتها الإنتاجية

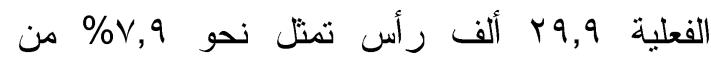
متوسط طاقتها الإنتاجية الفعلية في مصر البالغ

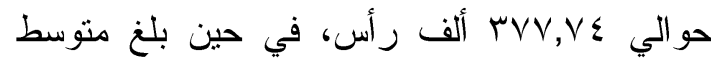

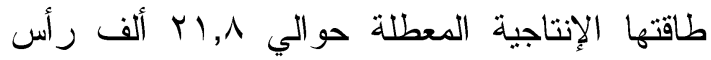
(نصف أعداد الطاقة الإنتاجية الكلية تقريباً) تمثل

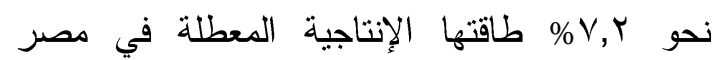

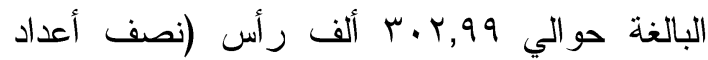
الطاقة الإنتاجية الكلية تقريباً). r- بلغت نسبة الطاقة المعطلة للطاقة الكلية في محافظة

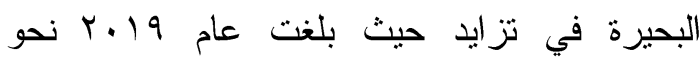

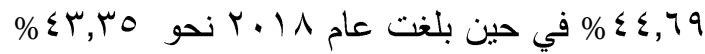
بزيادة تقدر بنحو ع ؟,1\%؛ بينما بلغت نسبة الطاقة

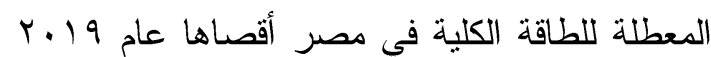

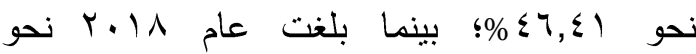

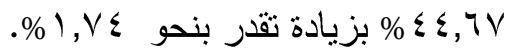

- أعداد الرؤوس من الإبل في محافظة البحيرة بلغ

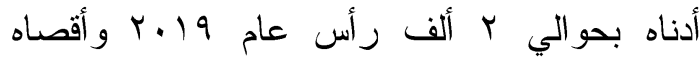

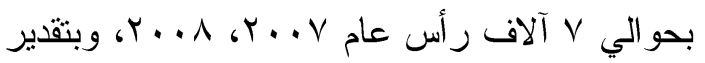
معدل التغير السنوي لأعداد الرؤوس من الأبل تبين أنه لم تتبت المعنوية احصائياً. ومما سبق وفقاً للأهمية النسبية تبين أن أعداد الأبقار

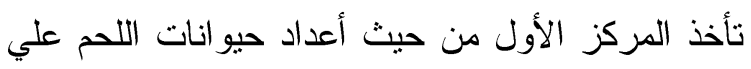
مستوي الجمهورية عامة ومحافظة البحيرة خاصة حيث ليث تبلغ r/ باليها أعداد الجاموس والأغنام و الماعز

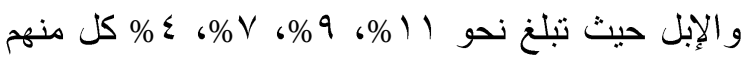
علي الترتيب. كما يتضح وجود إنخفاض في الكمية المنتجة من

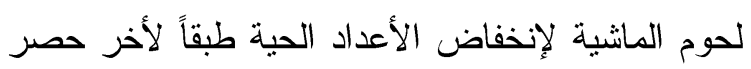

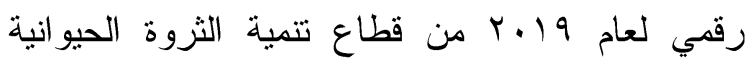
حيث يبلغ أعداد الأبقار و الجاموس والأغنام و الماعز

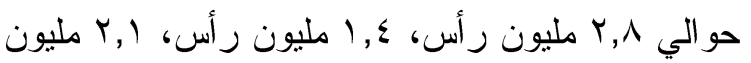

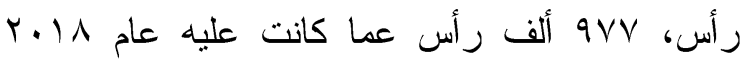

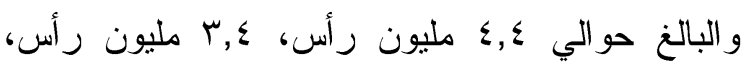

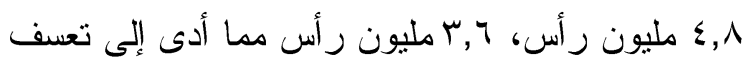

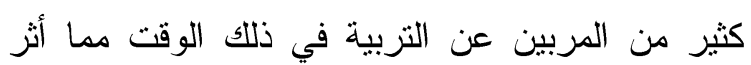
سلباً أيضاً علي العمالة في قطاع الإنتاج الحيو اني. ثالثاً: تقدير أعداد مزارع ماثشية التسمين والطاقية

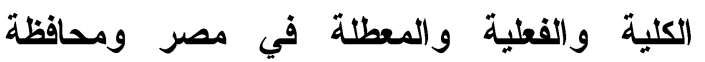

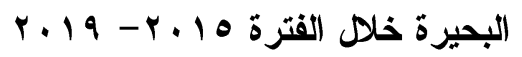

جدول r: أعداد مزارع ماثية التسمين العاملة والطاقة الإتتاجية الكلية والفعلية والمعطلة في مصر ومحافظة

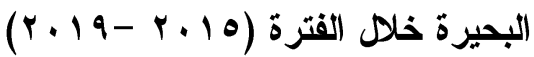

\begin{tabular}{|c|c|c|c|c|c|c|c|c|c|c|}
\hline \multicolumn{2}{|c|}{ نلطبة الطاقة المعلة المعلة } & \multicolumn{2}{|c|}{ الطاقة الإتتاجية المعطلة } & \multicolumn{2}{|c|}{ الطاقة الإنتاجية الفعلية } & \multicolumn{2}{|c|}{ الطاقة الإنتاجية الكلية } & \multicolumn{2}{|c|}{ أعداد المزارع } & \multirow[t]{2}{*}{ السنوات } \\
\hline البحيرة & الجمهورية & البحيرة & الجمهورية & البحيرة & الجمهورية & البحيرة & الجمهورية & البحيرة & الجمهورية & \\
\hline ru & $\{r, q 1$ & IVTV. & ry & rI $\varepsilon . \wedge$ & ro19 $\leqslant V$ & $\varepsilon q . \vee \wedge$ & 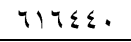 & 191 & $\wedge \leq \leq \wedge$ & $r .10$ \\
\hline$\varepsilon \cdot, 97$ & $\varepsilon r, V Y$ & $r \cdot \wedge 91$ & سR.r & $r .11 r$ & ryETrV & $01 \ldots r$ & บะVนฯ. & $19 \leqslant$ & $\Lambda V \leq Y$ & $r .17$ \\
\hline$\{0,04$ & $\varepsilon \leqslant, \leqslant 4$ & $r \leqslant 11 r$ & $\mathrm{r} .10 \mathrm{Vr}$ & YANIT & rVTV.V & orarA & TVAYVQ & $\wedge 9 \mathrm{~V}$ & $9 . \leqslant r$ & $r .1 \mathrm{~V}$ \\
\hline \& & $\varepsilon \varepsilon, T V$ & TYQVT & r19940 & r...ro & ra9rוl & or99V & VITrMy & 199 & $9 \leqslant 19$ & $r \cdot 11$ \\
\hline$\leqslant \leqslant, 79$ & \{\rceil$, \leqslant 1$ & (2) & $r \leq 09 r \leq$ & rА१५. & r৭9r^o & OKYAq & VEOr। 9 & 119 & 1...N & $r .19$ \\
\hline \multirow[t]{2}{*}{$\varepsilon r, 11$} & $\varepsilon \varepsilon, \varepsilon r$ & $r \mid \Lambda . r$ & $r . r 991$ & r9107 & rVVVTO & 01709 & $M A \cdot V Y V$ & 190 & $91 \leq V$ & المتوسط \\
\hline & & \multicolumn{2}{|c|}{$V_{6} Y$} & \multicolumn{2}{|c|}{$V_{6} 9$} & \multicolumn{2}{|c|}{$V_{6} y$} & \multicolumn{2}{|c|}{9.1} & $\%$ \\
\hline
\end{tabular}




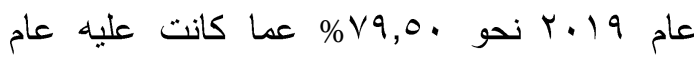

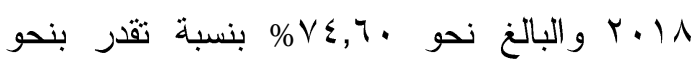

$. \% \leq, 9$

مما يأثر سلباً علي إنتاج مصانع أعلاف المانشية

وتتغيلها وبالتالي علي أعداد كبيرة من العمالة بها.

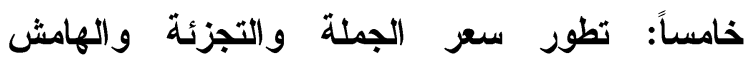
التسويقي للأبقار الحية في محافظة البحيرة خلال

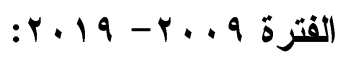

يتبين من الجدول (0) و الثكل رقم (ب) ما يلي: بدراسة تطور سعر الجملة للأبقار الحية في محافظة

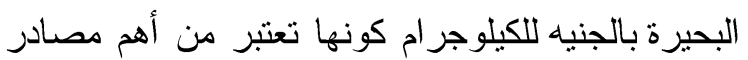

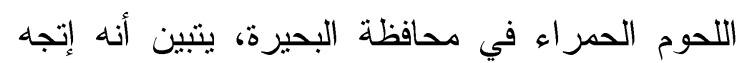

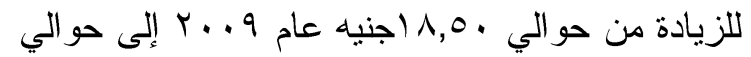

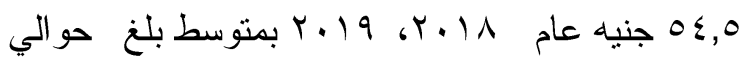

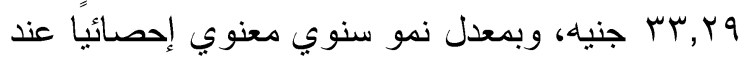

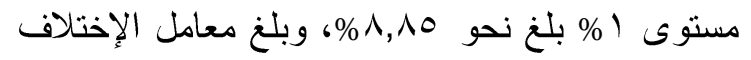

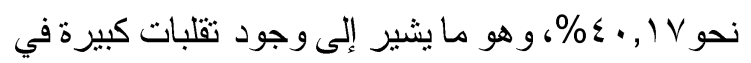

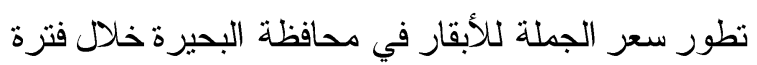

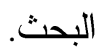
وقد اتجه سعر التجزئة للأبقار الحية في محافظة

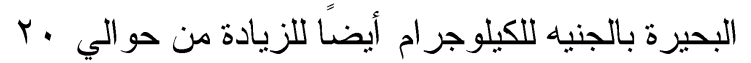

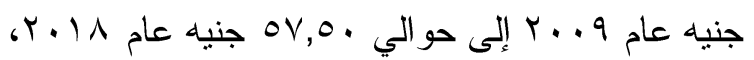
$6 r+19$
مما سبق يتضح أن نسبة متوسط الطاقة المعطلة للطاقة الكلية في محافظة البحيرة بالنسبة للجمهورية لفية لفئه

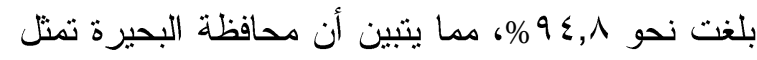
نسبة كبيرة بالنسبة للجمهورية؛ مما يتطلب الإهتمام

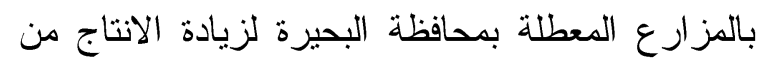

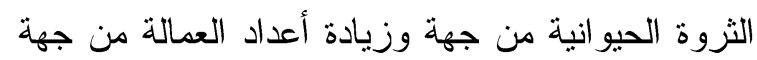

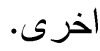
رابعاً: مصانع أعلاف الماشية والطاقة الإتتاجية الكلية و الفعلية و المعطلة في مصر ومحافظة البحيرة خلا

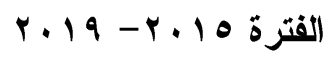

يتضح من الجدول (ع) أن:

- بلغ متوسط الطاقة الإنتاجية الكلية لمصانع الأعلاف لهن

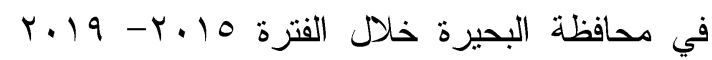

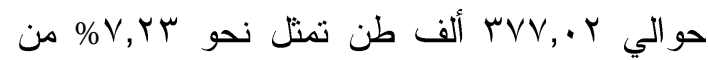

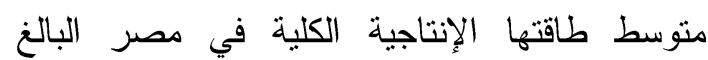
حوالي r, مليون طن ومتوسط طاقتها الإنتاجية

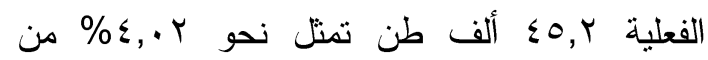
متوسط طاقتها الإنتاجية الفعلية في مصر البالغ حوالي ا, امليون طن، في حين بلغ منوسط طاقتها

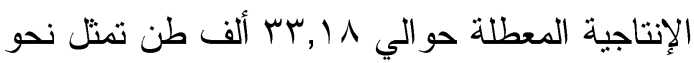

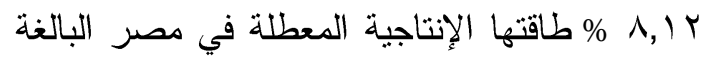
حوالي ا,ـ مليون طن. حيث تبين أن نسبة الطاقة

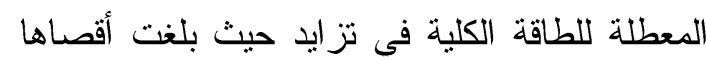

جدول ع: مصانع أعلاف الماثية العاملة والطاقة الإنتاجية الكلية والفعلية والمعطلة في مصر ومحافظة البحيرة

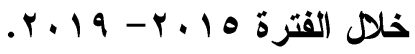

\begin{tabular}{|c|c|c|c|c|c|c|c|c|}
\hline \multicolumn{2}{|c|}{ نسبة الطاقة المعطلة } & \multicolumn{2}{|c|}{ الطاقة الإنتاجية المعطلة } & \multicolumn{2}{|c|}{ الطاقة الإنتاجية الفعلية } & \multicolumn{2}{|c|}{ الطاقة الإنتاجية الكلية } & \multirow[t]{2}{*}{ السنوات } \\
\hline البحيزة & الجمهورية & البحيرة & الجمهورية & البحيرة & الجمهورية & البحيرة & الجمهورية & \\
\hline$\wedge 9,7$ & $\lambda I, V 1$ & rTVAY. & rTVY.r. & rqY.. & Arr.rq & TVV.r. & $\leqslant \leqslant 99.09$ & $r .10$ \\
\hline$\Lambda \Lambda, 0 Y$ & $V q, r$ & TrTVAO & 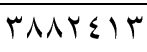 & ETYTO & $1 \ldots r \wedge \wedge \lambda$ & TVV.r. & $\varepsilon \wedge \wedge \circ H_{1}$ & $r .17$ \\
\hline$\Lambda V, \Sigma\rceil$ & $V V, 04$ & rrqvo. & $\varepsilon \cdot \wedge \wedge \vee q 4$ & $\varepsilon V Y V$. & $11 A T V \leqslant V$ & TVV.r. & OYVIOST & $r .1 V$ \\
\hline$\Delta V, \varepsilon r$ & $V \varepsilon, T$ & rरq4r. & हावरा १V & $\varepsilon \vee r q$. & $1 \leqslant$ I १. & TVV.r. & OYYAY.T & $r .11$ \\
\hline$\Delta V, \cdot r$ & $\vee 9,0$ & rYAIT. & 20979.1 & $\{\wedge \wedge q$. & $1110 \leqslant 00$ & $r V V \cdot r$. & OVNYMTY & $r .19$ \\
\hline \multirow[t]{2}{*}{$\Lambda \Lambda, \cdot 1$} & $\vee q$ & & $\varepsilon . \wedge \wedge 0 . q$ & $\leqslant 019 V$ & $11 Y \leqslant V 10$ & $r V V \cdot r$. & OrITYGs & المتو سط \\
\hline & & \multicolumn{2}{|c|}{$\lambda, 1 Y$} & \multicolumn{2}{|c|}{$\varepsilon, \cdot Y$} & \multicolumn{2}{|c|}{$V, Y r$} & $\%$ \\
\hline
\end{tabular}


جدول ه: تطور سعر الجملة وسعر التجزئة والهامش التسويقي المطلق والنسبي ونصيب المنتج و الوسطاء من جنيه

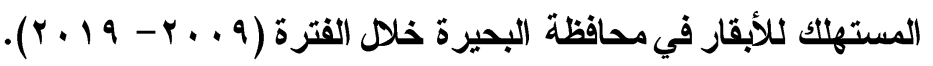

\begin{tabular}{|c|c|c|c|c|c|c|c|}
\hline \multicolumn{3}{|c|}{ توزيع جنيه المستهلت } & \multirow{2}{*}{ الجسبة بين التبزئة التسويقي } & \multirow{2}{*}{ 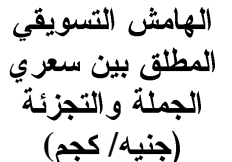 } & \multirow{2}{*}{ (التجزئة } & \multirow{2}{*}{ (جنملة } & \multirow[t]{2}{*}{ السنوات } \\
\hline نصيب تاجر & نصيب تاجلة & نصنبِ & & & & & \\
\hline$V, 0$ & 0 & $\Lambda \mathrm{Y}, \mathrm{O}$ & $\mathrm{v}, \mathrm{o}$ & 1,0 & $r$. & 11,0 & r...q \\
\hline$Y, r Y$ & 1, YO $_{0}$ & $\Lambda \leqslant, 0 \leqslant$ & $Y, Y Y$ & 1, Vo & $Y \leq, Y_{0}$ & $r, 0$ & $r+1$. \\
\hline$\varepsilon, \lambda)$ & $\varepsilon, \wedge)$ & $9 \cdot, r \wedge$ & $\varepsilon, \lambda)$ & 1, ro $_{0}$ & r4 & $T \leqslant, V_{0}$ & $r .11$ \\
\hline 0,19 & $r, r$ & 91,01 & 0,19 & $1, \pi \wedge$ & $r 4,0$ & ro, Tr & $r \cdot I r$ \\
\hline 0,07 & 1,10 & 94,09 & 0,07 & 1,0 & tr & ro,o & $r .14$ \\
\hline 7,9 & $0,1 \mathrm{~V}$ & $\Delta V, q \mu$ & 7,9 & $r$ & rq & tr & $r \cdot 1 \leqslant$ \\
\hline $0,9 \mathrm{~V}$ & $\varepsilon, \leqslant \wedge$ & 19,00 & $0,9 \mathrm{~V}$ & r & $\mu \mu, 0$ & $r 1,0$ & $r .10$ \\
\hline$V, r_{0}$ & ז'וד & $\Lambda \uparrow, r \mu$ & $V, r_{0}$ & $r, 0$ & $r \varepsilon$ & $\mu, 0$ & $r .17$ \\
\hline$r, 00$ & $r, 9 V$ & $9 \leqslant, \leqslant \wedge$ & $r, 00$ & $1, \pi \mu$ & or,Ir & $0 \cdot, 1$ & $r . I V$ \\
\hline $0, Y_{Y}$ & $1, V \leqslant$ & $9 \mu, . \leqslant$ & $0, Y_{Y}$ & $r$ & $O Y, 0$ & $0 \leqslant, 0$ & $r .11$ \\
\hline $0, Y Y$ & $r, \leqslant \wedge$ & $91, r$ & $0, r Y$ & $r$ & Or,o & $0 \leqslant, 0$ & $r .19$ \\
\hline $0, \mathrm{VV}$ & $\varepsilon, r \mu$ & $\wedge 9,9$ & $0, \mathrm{VV}$ & $1,9 \pi$ & rO, rY & $r \mu, r q$ & المتوسط \\
\hline \multirow[t]{2}{*}{ Yo, YY } & $\{0, Y \uparrow$ & $r, \leqslant 0$ & YO, Yr & $\mu, \leqslant 0$ & ra, IV & $\varepsilon \cdot, l \vee$ & معامل الإختلاف (\%) \\
\hline & & & (.) $(1, r q)$ & "r,AY & $"$ "* $q, r \leqslant$ & ${ }^{*} \wedge, \wedge \circ$ & معدل التغير (\%) \\
\hline
\end{tabular}

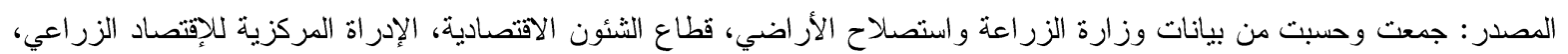
نشرة الأسعار الزر اعية، أعداد مختلفة.

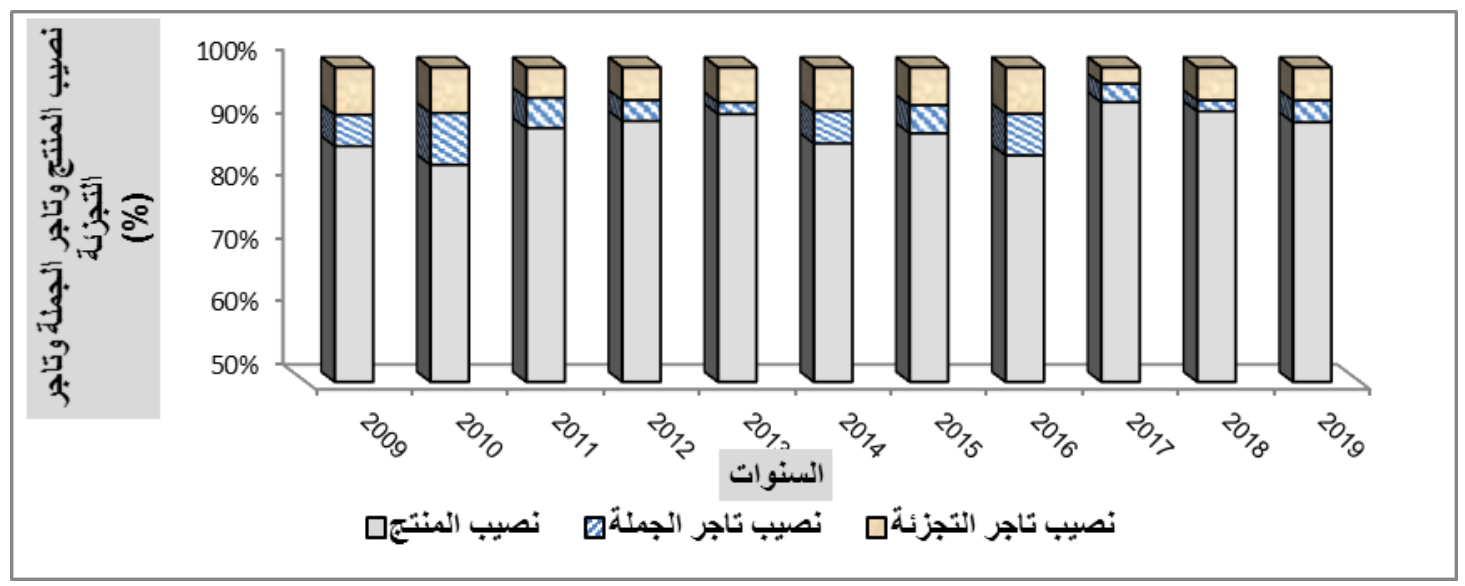

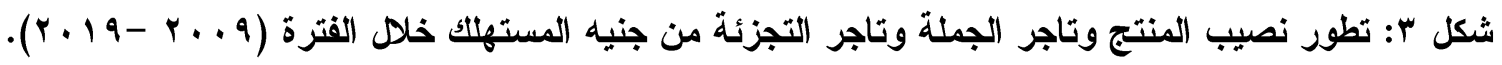
فقد تنين أنه اتجه للزيادة من حوالي مب, اجنيه عام وذلك بمتوسط بلغ حوالي Y Y Y T جنيه، وبمعدل نمو

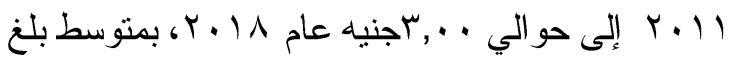

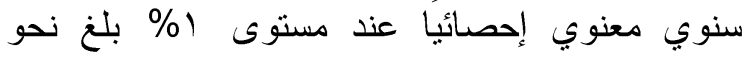
حو الي سو, ا جنيه، وبمعدل نمو سنوي معنوي إحصائيًا

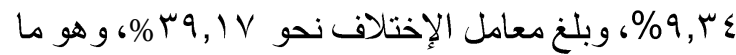

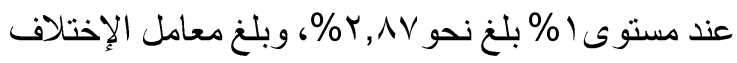

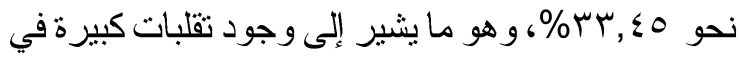
يشير إلى وجود تقلبات كبيرة في تطور سعر التجزئة لكأبقار بمحافظة البحيرة خلال فتزة البحث. تطور الهامش التسويقي المطلق للأبقار في محافظة

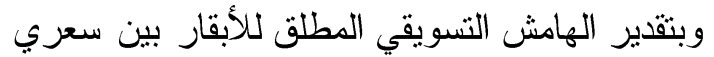

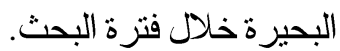

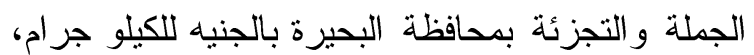


لذا فقد تم تقدير العلاقة السعرية بين سعر التجزئة وسعر الجملة PriceR

\section{PriceR = 2.60 + 0.027 PriceW}

$$
\left.\mathrm{F}=506.11^{* * *}\right)^{* * *} \quad(22.50)^{* * *}
$$

يتضح من الدالة السابقة وجود ارتباط شبه تام بينهما، حيث بلغ معامل التحديد حو الي 919 , •، مما يشير إلى أن

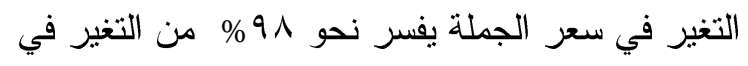
مستوى سعر التجزئة، وثبتت معنوية هذه الدالة إحصائيًا عند مستوى l +,., وتبين منها أنه إذا زاد سعر الجملة

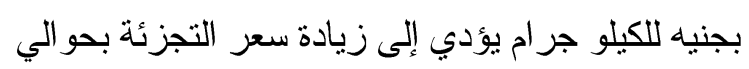

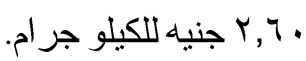
سادساً: أهم المشاكل الإنتاجية والتسويقية التي تواجه جله مربي عجول التسمين في محافظة البحيرة.

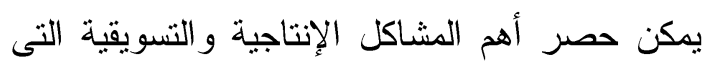
أدت لتذبذب أسعار اللحوم الحمر اء بمحافظة البحيرة

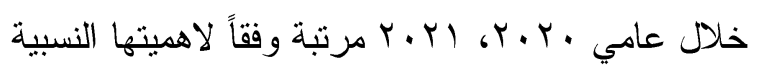
وفقاً لآراء المربين بالعينة البحنية التى تضمنها البحث فيما يلى: - ميلى أولاً: أسباب إنخفاض أسعار اللحوم الحمر اء: بإسنطلاع آراء مربي عجول التسمين بالعينة البحثية

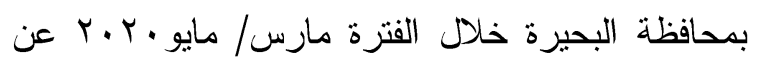
الأسباب و العوامل التي أدت الي إنخفاض أسعار عجول التسمين في السوق وترتيب تلك الأسباب وفقاً للأهميتها النسبية تبين من الجدول(آ) أن:

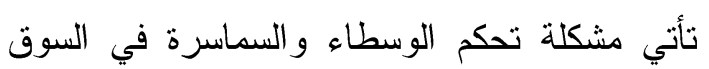
و الأسعار في المرتبة الأولي بالنسبة للمشاكل التي تواجه

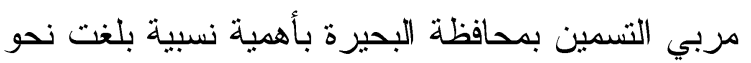

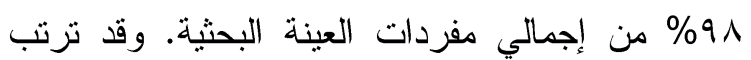
علي ذلك ضعف قدرة المنتجين علي التسويق نظراً لإنتشار السماسرة والوسطاء في تسويق عجل اللحم

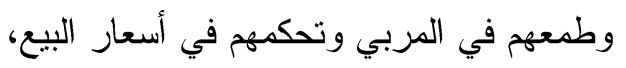

وفيما يتعلق بتطور الهامش التسويقي النسبي للأبقار بين سعري الجملة و التجزئة بمحافظة البحيرة، فقد شهد

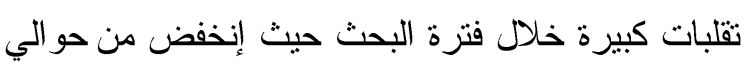
\% V,0.0.

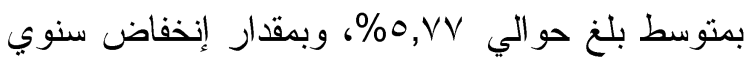

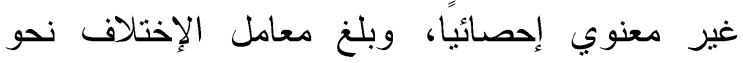

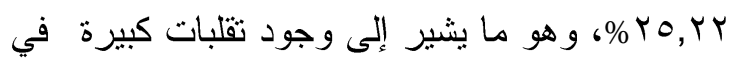

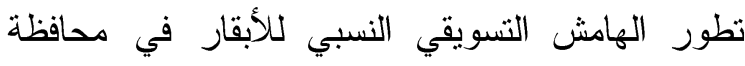

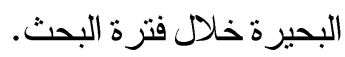
وفيما يتعلق بنصيب المنتج من جنيه المستهلك فهو لهودي

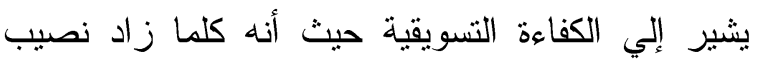
المنتج من جنيه المستهلك كلما زادت الكفاءة التسويقية،

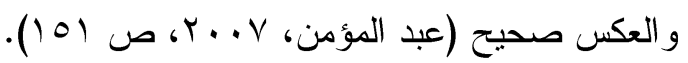

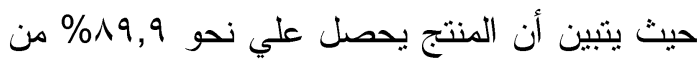
جنيه المستهلك كمتوسط للفترة 9. .. حين يحصل تاجر الجملة علي سب,ء\% ويحصل

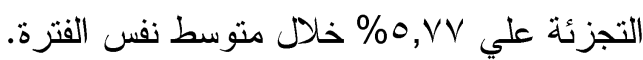
وقد انخفض نصيب المنتج من جنيه المستهلك عام

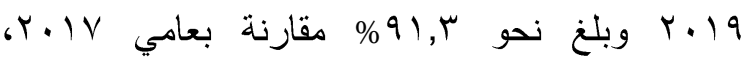

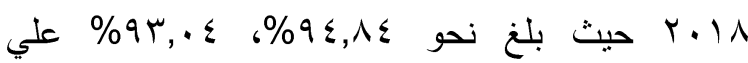
التو الي، وبالتالي نتيجة لإنخفاض نصيب المنتج من جنيه المستهلك عام 9 ــ ب تتخفض الكفاءة التسويقية. العلاقة السعرية بين سعر التجزئة وسعر الجملة خلا

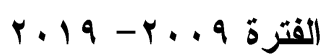
وحيث أن الأسعار تُعد المتغير الرئيسي في توجيه وتخصيص وتوزيع المو ارد المتاحة بين مختلف مجالات الإنتاج، وتلعب دورًا رئيسيًا في تتظيم عملية الإنتاج وتحديد أنو اع المنتجات من السلع و الخدمات وكيفية إنتاج هذه المنتجات وتوزيعها بين المستهلكين،وفي تونين هين هيكل الإستهلاك من السلع و الخدمات إلى الوجهة التي يرغبها

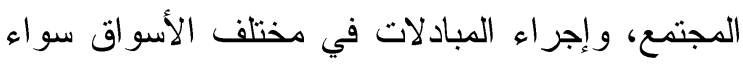

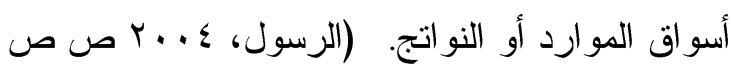

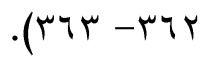


جدول ؟َ: العوامل والأسباب التي أدت إلي انخفاض أسعار عجول التسمين في السوق وفقاً لآراء مربي عجول

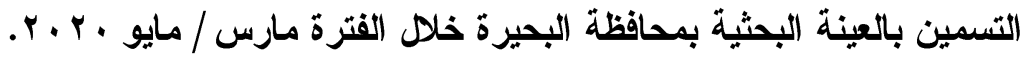

\begin{tabular}{|c|c|c|c|}
\hline$\%$ & العدد (ن = . . 1 1) & المشكلة & م \\
\hline 91 & 91 & تحكم الوسطاء و السماسرة في السوق و الأسعار & 1 \\
\hline 94 & 94 & زيادة المعروض من العجول المستوردة & r \\
\hline$\Lambda \Lambda$ & $\Lambda \Lambda$ & إصابة عجول التسمين ببعض الأمر اض & $r$ \\
\hline$\Lambda \varepsilon$ & $\Lambda \varepsilon$ & زيادة طول مدة التسمين & $\varepsilon$ \\
\hline
\end{tabular}

المصدر: جمعت وحسبت من بيانات إستمارة الإسنيبان للعينة البحثية بأسواق اللحوم الحمراء بمحافظة البحيرة من إعداد الباحثين خلال

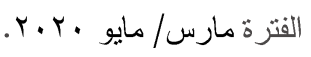

النسمين في السوق وترتيبها وفقاً لأهميتها النسبية تبين

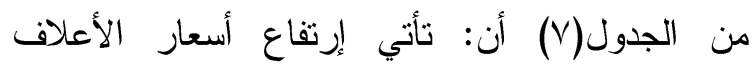

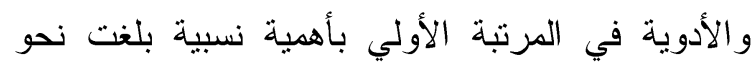
ب9\% من إجمالي عدد مزارع العينة البحثية، يليها

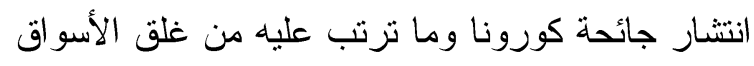
و انخفاض المعروض من اللحوم وانخفاض إستيراد الماثية و اللحوم المجمدة في المرتبة الثانية بأهمية نسبية بلغت نحو و\% من إجمالي عدد مزارع العينة البحثية،

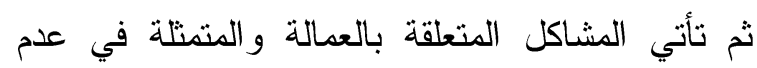
تو افر الأيدي العاملة المدربة وإرتفاع أجورها في

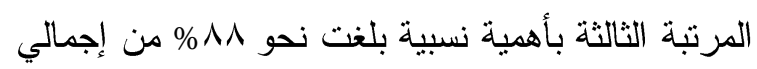

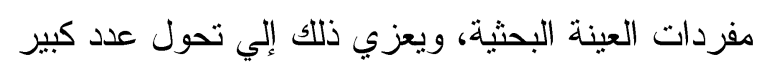

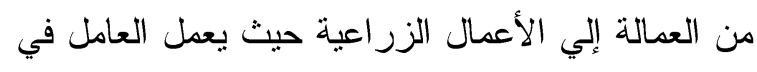

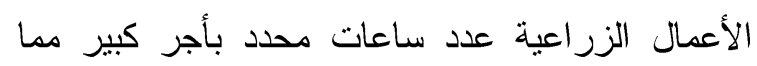
يجعله يتمكن من العمل بأكثر من وردية في اليوم

الو احد
بالإضافة لرفضهم الثراء بالوزن مما أدى إلي قبول

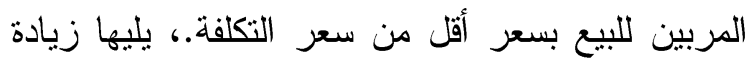
المعروض من العجول المستوردة جاء في المرتبة الثانية بأهمية نسبية بلغت نحو سوض من من إجمالي عدد

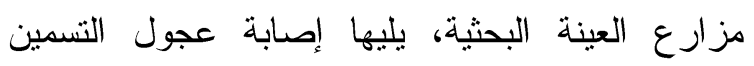

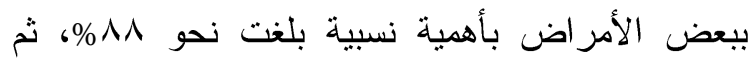

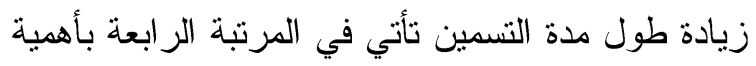
نسبية بلغت نحو ع^\% من إجمالي عدد مزارع مدة العينة البحثية، وقد ترتب علي هذه العوامل و الأسباب سالفة الذكر انخفاض سعر بيع للعجول وزيادة التكاليف الإنتاجية، الأمر الذي ترتب عليه إنخفاض العائد من لن التسمين و إضطر ار المربين للبيع بسعر أقل من سعر الإنه التكلفة. ثانياً: أسباب إرتفاع أسعار اللحوم الحمراء: بإستطلاع آراء مربي عجول التسمين بالعينة البحثية

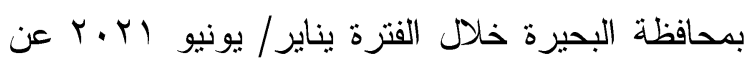

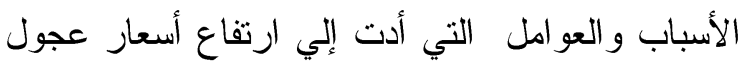

جدول V: العوامل والأسباب التي أدت إلي إرتفاع أسعار عجول التسمين في السوق وفقاً لآراء مربي عجول

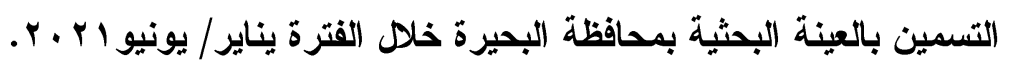

\begin{tabular}{|c|c|c|c|}
\hline$\%$ & العدد (ن = = 1 ) & المشكلة & م \\
\hline $9 \pi$ & $9 r$ & إرتفاع أسعار الأعلاف و الأدوية & $\frac{1}{1}$ \\
\hline 9 . & 9 . & إنتشار جائحة كورونا و إنتشار الأمر اض & $r$ \\
\hline$\wedge \wedge$ & $\wedge \wedge$ & مشاكل متعلقة بالعمالة & $r$ \\
\hline$\Lambda$. & $\Lambda$. & مشاكل متعلقة بموقع المزرعة & $\varepsilon$ \\
\hline$\varepsilon \wedge$ & $\varepsilon \wedge$ & زيادة الطلب علي اللحوم الحمرء في المناسبات الدينية & 0 \\
\hline
\end{tabular}

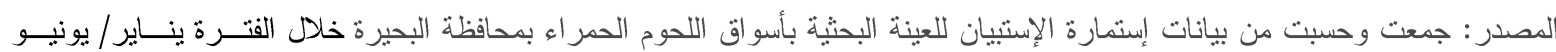


المركزى للمساهمة في حل مشكلة البطالة وتوفير

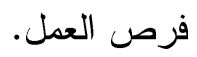

\section{المراجع}

أحمد أبو اليزيد الرسول، السياسة الاقتصادية الزراعية

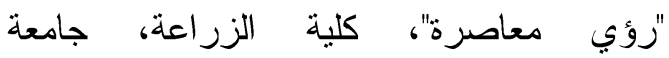
الإسكندرية، مكتبة بستان المعرفة، الإسكندرية،

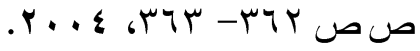

أحمد حسن أبو شامة عبد الصادق، الكفاءة الإنتاجية للحوم

الحمراء في محافظة الوادي الجديد، المجلة

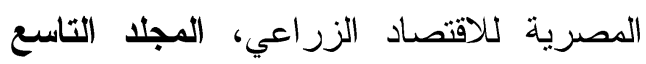

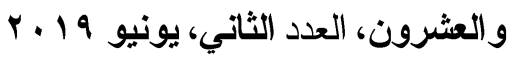

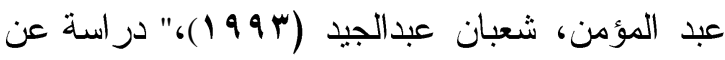

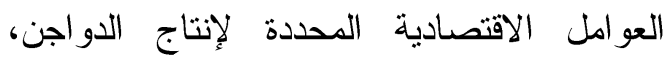
جمهورية مصر العربية"، رسالة ماجستير، قسم الاقتصاد الزر اعي، كلية الزر اعة، جامعة الأزهر . علاء الدين مصطفى المنوفي وآخرون، التخطيط الإستراتيجي لمستقبل قطاع اللحوم الحمراء في

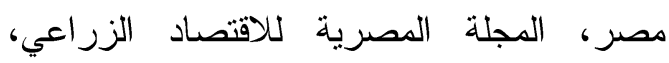

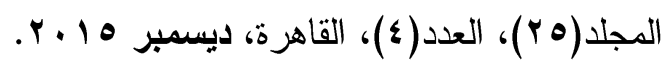
علي عاصم عبد العزيز وآخرون، دراسة تحليلية للطلب علي اللحوم الحمراء في مصر (دراسة حالة في محافظة بني سويف)، المجلة المصرية

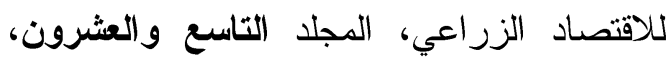
العدد الثاني، يونيو 9 1. ب. منى محمود محمد مكاوي، دراسة اقتصادية للطاقة

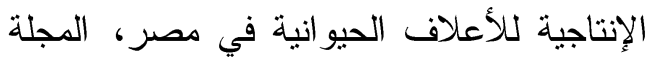
المصرية للاقتصاد الزراعي، المجلد التاسع و العشرون، العدد الثاني، يونيو 9 1 ـr. ناصر محمد عبد العال سالمان، الكفاءة الاقتصادية لإنتاج و استهلاك اللحوم الحمر اء فى مصر، المجلة المصرية للاقتصاد الزراعي، المجلد التاسع و العشرون، العدد الأول، مارس 9 1. ب.
وبالتالي زيادة العائد المادي والأجر الذي يحصل عليه من هذا العمل الذي يكون ضعف أجره تقريباً من العمل في مزارع تسمين عجل اللحم، ثم تأني المشاكل المتعلقة بموقع المزرعة والمتمثلة في زيادة تكاليف الوصول

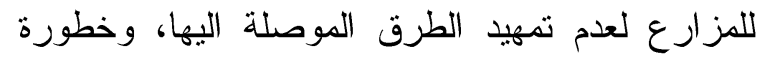
نقل الأمر اض أثناء نقل عجول من السوق للمزرعة في في

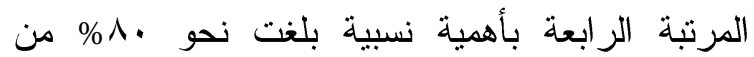

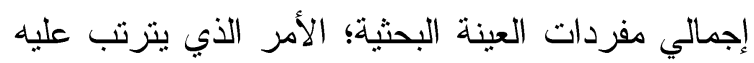

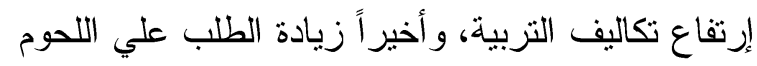
الحمراء في المناسبات الدينية في المرتبة الخامسة والأخيرة بأهمية نسبية بلغت نحو $48 \%$ من إجمالي

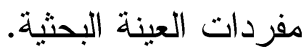
في ضوء النتائج التي توصل إليها البحث وللمحافظة على إستقرار وثبات أسعار اللحوم الحمر اء في الأسواق المصرية بصفة عامة ومحافظة البحيرة بصفة خاصة فإنه يقترح اتخاذ الإجر اءات و التدابير التالية: (1) التوسع في المشروع القومي للبتلو ومضاعفة حجمه لزيادة الإنتاجية من اللحوم الحمر اء وقد ضخت

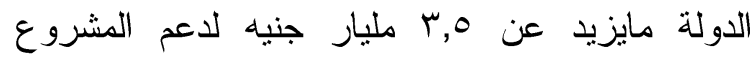

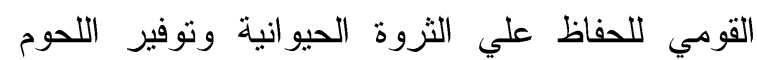

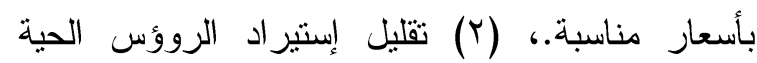

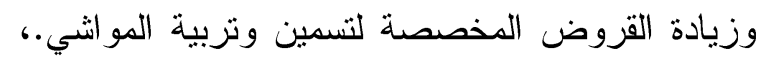

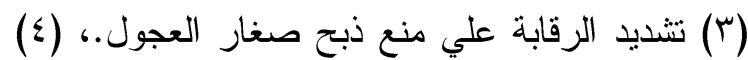
توفير الأمصال والأدوية البيطرية والسلالات المحسنة من الماثية.، (0) إستبراد كميات كافية من اللحوم لإدية المبردة و المجمدة لزيادة المعروض وإناحة البدائل أمام المستهلك لمواجهة زيادة الطلب علي اللحوم الحمراء

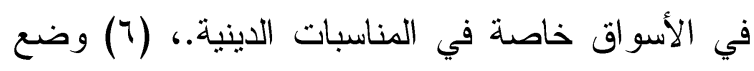
خريطة و اقعية للمشاكل التى تواجه مربي الماشية

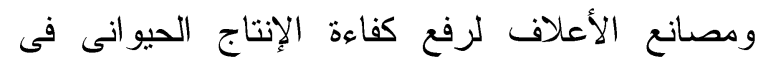
مصر وزيادة إنتاج اللحوم الحمر اء وزيادة فرص تنشغيل العمالة.، (V) دعم المشروعات الصغيرة للإنتاج الحيوانى وتقديم التسهيلات لها ضمن مبادرة البنك 


$$
\text { وزارة الزراعة واستصلاح الأراضي، قطاع الثنئون }
$$

Shabbir,Rizwan, (2011). "Sustainable Growth in Livestock Sector: A Case Study of Pakistan." Lund University, Sweden, June.

Thompson, P.B. and Nardoneb, A., (1999). "Sustainable Livestock Production: Methodological and Ethical Challenges. "Livestock Production Science Vol. 61.

$$
\begin{aligned}
& \text { وزارة الزراعة وإستصلاح الأراضى، قطاع الشئون } \\
& \text { الإقتصادية، نشرة إحصاءات الثروة الحيوانية، }
\end{aligned}
$$

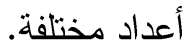

$$
\begin{aligned}
& \text { وزارة الزراعة واستصدلاح الأراضي، قطاع الثئون }
\end{aligned}
$$

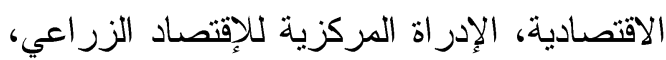

$$
\begin{aligned}
& \text { نشرة الأسعار الزر اعية، أعداد مختلفة. }
\end{aligned}
$$

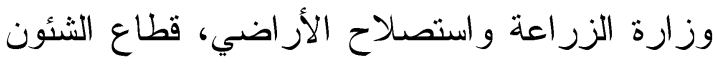

$$
\begin{aligned}
& \text { الاقتصادية، نشرة الدخل الزراعي، أعداد مختلفة. }
\end{aligned}
$$

\title{
The Effect of Red Meat Price Fluctuations on Employment (A case Study of the Buhaira Governorate)
}

\author{
Kamal Salama, Elham shabaan abd El -salam pargal, \\ Doaa Ibrahim abd El- hamid hashem \\ Agricultural Research Center
}

\begin{abstract}
The study aimed to identify the most important factors and reasons that led to the fluctuation of meat prices in Egyptian markets specially in Beheira Governorate, which affected on the employment in Beheira Governorate to find solutions and proposals that would maintain the stability of red meat prices in the Egyptian market by studying the following sub-objectives.

The study reached several results, the most important of which are: (1)The average value of red meat production in Egypt compared to the value of agricultural production and animal production was about $13.4 \%$ and $36.27 \%$, respectively, during the study period. that means the value of red meat production from livestock comes at the forefront of animal production. (2) decreasing of quantity produced of livestock meat as a result of decreasing of the live numbers according to 2019 from the livestock development sector, where the number of cows, buffaloes, sheep and goats is about 2.8 million head, 1.4 million head, 2.1 million head, 977 thousand head than it was in 2018 which was estimated about 4.4 million head, 3.4 million head, 4.8 million head, 3.6 million head so from the previos result it was led to the reluctance of many breeders from breeding at that time, which also negatively affected on employment in the animal production sector. (3) The average of idle capacity of the total energy in Beheira governorate copared to the Republic estimated about $94.8 \%$, which negatively affected on the production and operation of farms and thus on large numbers of workers and the flight of a large number of workers from the animal production sector to other sectors. (4) It was found that more than two-thirds of the total production capacity of livestock feed factories in Egypt is idle, which negatively affected on the production and operation of livestock feed factories in Egypt and, consequently, large numbers of workers. (5) The producer's share of the consumer's pound decreased in 2019 and amounted about $91.3 \%$ compared to the years 2017 and 2018, which amounted to about $94 \% .84,93.4 \%$, respectively, as a result of decreasing the share of the producer from the consumer pound in 2019 , the marketing efficiency decreases.
\end{abstract}

